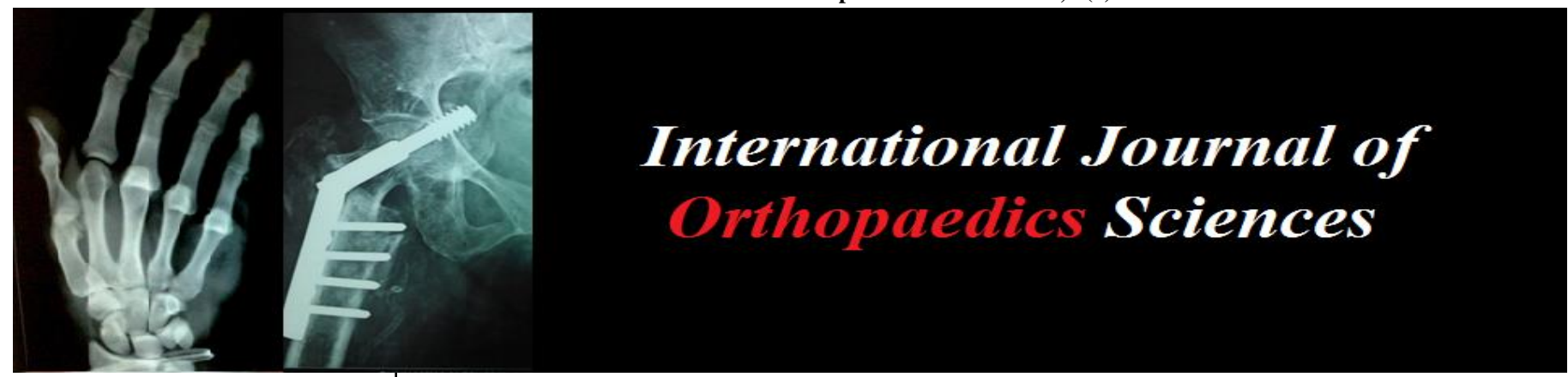

E-ISSN: 2395-1958

P-ISSN: 2706-6630

IJOS 2020; 6(1): 190-195

(C) 2020 IJOS

www.orthopaper.com

Received: 11-11-2019

Accepted: 15-12-2019

Rejo Varghese Jacob

D. Ortho, DNB (Ortho), Senior

Resident Orthopedics, Hindu

Rao Hospital \& NDMC Medical

College, Delhi, India

Gaurav Kumar Gupta

DNB (Ortho), Senior Resident

Orthopedics, Rao Tula Ram

Hospital, Delhi, India

\section{Jacob Mathew}

M.S Ortho, Associate Professor

Orthopedics, Calicut Medical

College, Kerala, India

Reema Miria Abraham

MD Pathology, Calicut Medical

College, Kerala, India
Corresponding Author:

Rejo Varghese Jacob

D. Ortho, DNB (Ortho), Senior

Resident Orthopedics, Hindu

Rao Hospital \& NDMC Medical

College, Delhi, India

\section{Nontraumatic myositis ossificans of elbow as a sequelae of tetanus: A rare case}

\author{
Rejo Varghese Jacob, Gaurav Kumar Gupta, Jacob Mathew and Reema \\ Miria Abraham
}

DOI: $\underline{\text { https://doi.org/10.22271/ortho.2020.v6.i1d.1860 }}$

\section{Abstract}

Myositis ossificans is a reactive process with proliferation of fibroblast, cartilage and bone within a muscle and is usually seen after trauma. We present an extremely rare case of nontraumatic myositis ossificans of right elbow post tetanus infection. The patient was admitted and treated for tetanus in medicine department and was referred to orthopedics department with swelling and restricted movement around right elbow four months after infection and was confirmed to be myositis mass on radiograph. The patient was started on elbow mobilization exercises till the active phase was over. Excision of the myositis mass was performed 14 months after infection and was started on range of movement exercises with good functional range at follow-up. We conclude that myositis ossificans as a sequelae of tetanus is an extremely rare finding with 9 such reported cases in literature and surgical excision and assisted physiotherapy gives good functional results in such patients.

Keywords: Non traumatic myositis ossificans, tetanus, posterior approach elbow

\section{Introduction}

Myositis ossificans is a reactive process involving progressive heterotopic bone formation and is usually seen after trauma with a prevalence of 1 in 1 million patients ${ }^{[1,7]}$. Non traumatic myositis ossificans is rare in literature ${ }^{[2]}$. Myositis ossificans after tetanus infection is an extremely rare finding seen only in places endemic for tetanus with only one such reported case in the India. We present such a case of non traumatic myositis ossificans of right elbow in a 22 year old patient after tetanus infection.

\section{Materials and Methods}

22 year male patient came to medical emergency with complaints of trismus, dysphagia and generalized muscle rigidity following a nail injury to right leg. He was admitted to the Intensive Care Unit and kept on mechanical ventilation. Injection tetanus immunoglobulin given and anticonvulsants and muscle relaxants were given. Patients general condition improved and was removed from mechanical ventilation and discharged from medicine department 1 month after admission.

He presented to orthopedic emergency 2 months after admission with complaint of stiffness around right elbow. On examination there was swelling around right elbow and reddish discolouration of skin around the elbow. On palpation, diffuse mass was palpable on the posterior aspect of right elbow $6 * 5 \mathrm{~cm}$ in size. Local rise of temperature was present and swelling was immobile and fixed to the underlying bone. The elbow had a flexion deformity of $25^{\circ}$ with further flexion upto $60^{\circ}$. Neurological and vascular examination was normal. Radiographs were taken and showed ossification on the posterior aspect of right elbow suspected to be a myositis mass. Routine blood investigations were sent and showed Total WBC count- 12500 cells/mm [3], CRP-negative, ESR-42mm/hr. The patient was started on range of movement exercises and Tablet indomethacin $50 \mathrm{mg}$ once daily for 2 weeks. The patient was followed up in orthopedic out patient department and range of movement exercises were continued until the swelling reached a quiescent stage.

The patient was admitted 14 months after infection and on clinical examination showed a flexion deformity of $25^{\circ}$ with further flexion upto $80^{\circ}$. Routine investigations showed Total 
WBC count- 8000 cells/mm ${ }^{[3]}$, ESR- $12 \mathrm{~mm} / \mathrm{hr}$, CRP-negative, Serum Alkaline Phosphatase-212 IU. Computed Tomography was done and showed ossification on the posterior and lateral aspects of distal humerus extending onto the olecranon. Excision and biopsy of suspected myositis mass was planned along with arthrolysis of elbow joint. Posterior midline incision was taken and ulnar nerve secured and retracted. Triceps was lifted from the posterior humerus and suspected myositis mass was found over the posterior and lateral aspect of distal humerus extending onto olecranon. Excision of the myositis mass and arthrolysis of elbow joint was performed. Full range of flexion and extension was achieved on table. Excised mass was sent for biopsy. Biopsy showed zonal phenomena with central cellular area, intermediate zone of osteoid and peripheral shell of highly organized bone confirming myositis ossificans.

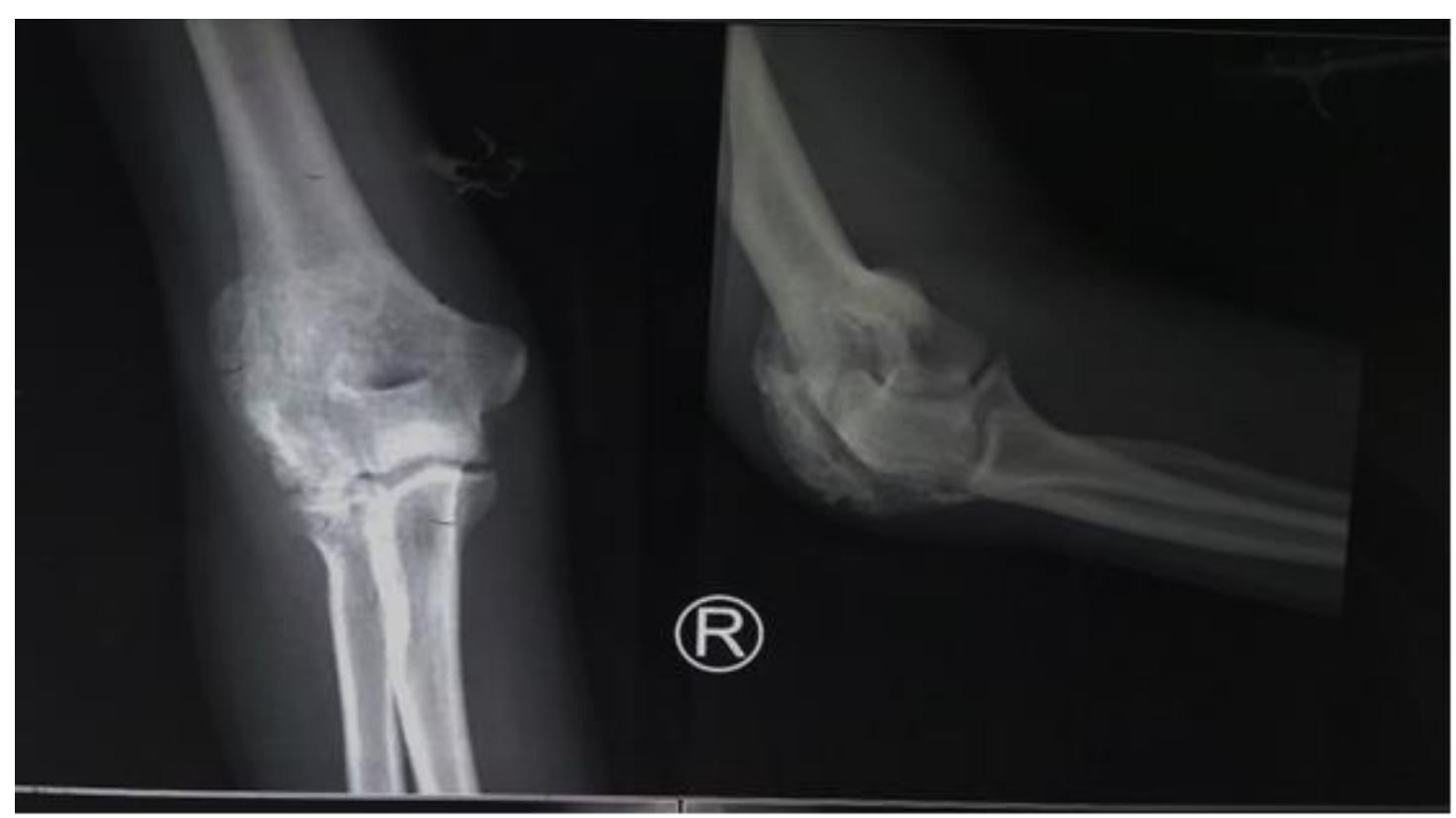

Fig 1: Pre-operative radiograph of right elbow AP and Lateral views taken 2 months after tetanus infection showing ossification arising from posterior aspect of humerus extending upto olecranon

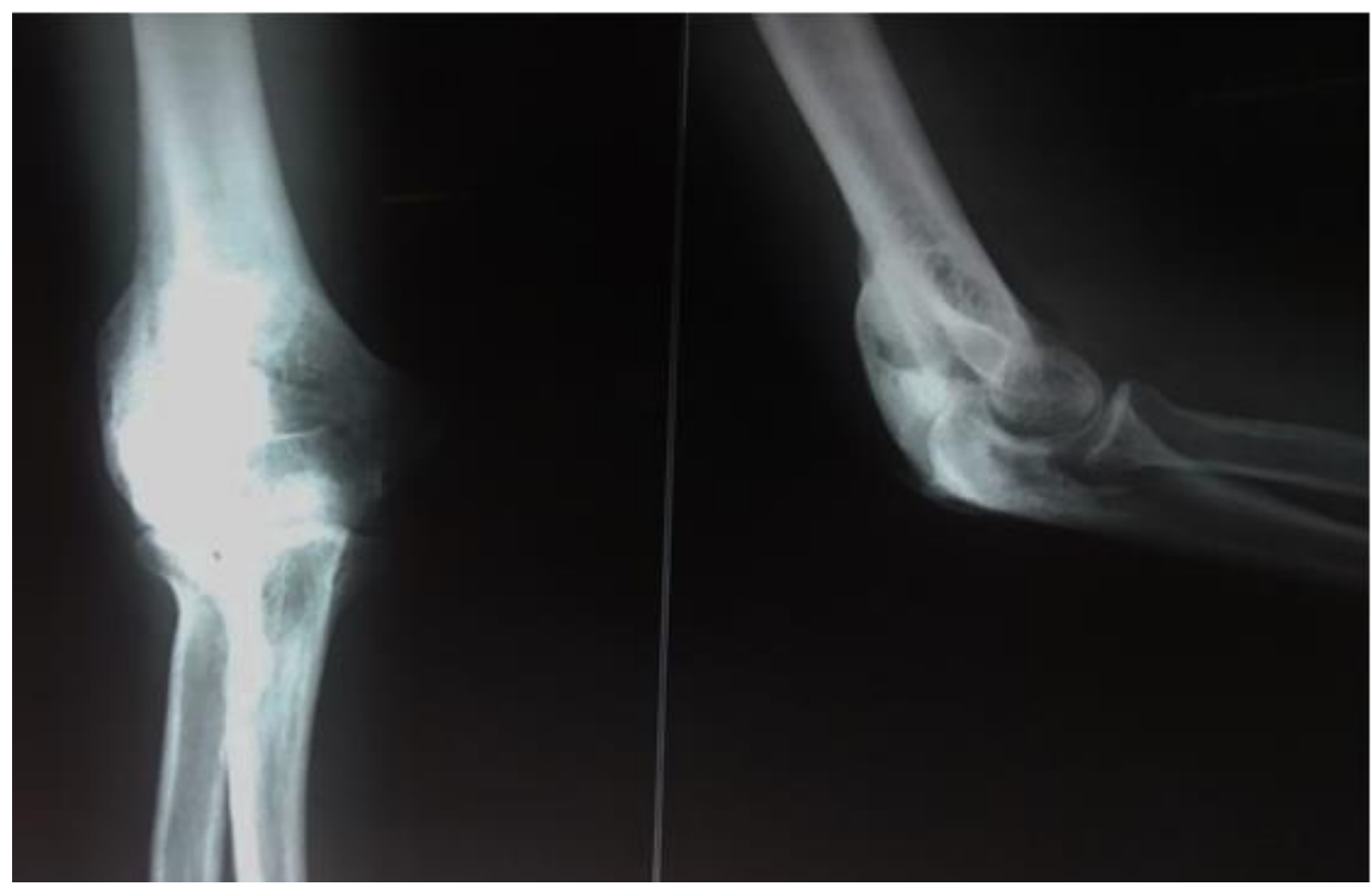

Fig 2: Pre-operative radiograph of right elbow AP and lateral views taken just before surgical procedure (14 months after tetanus infection). 

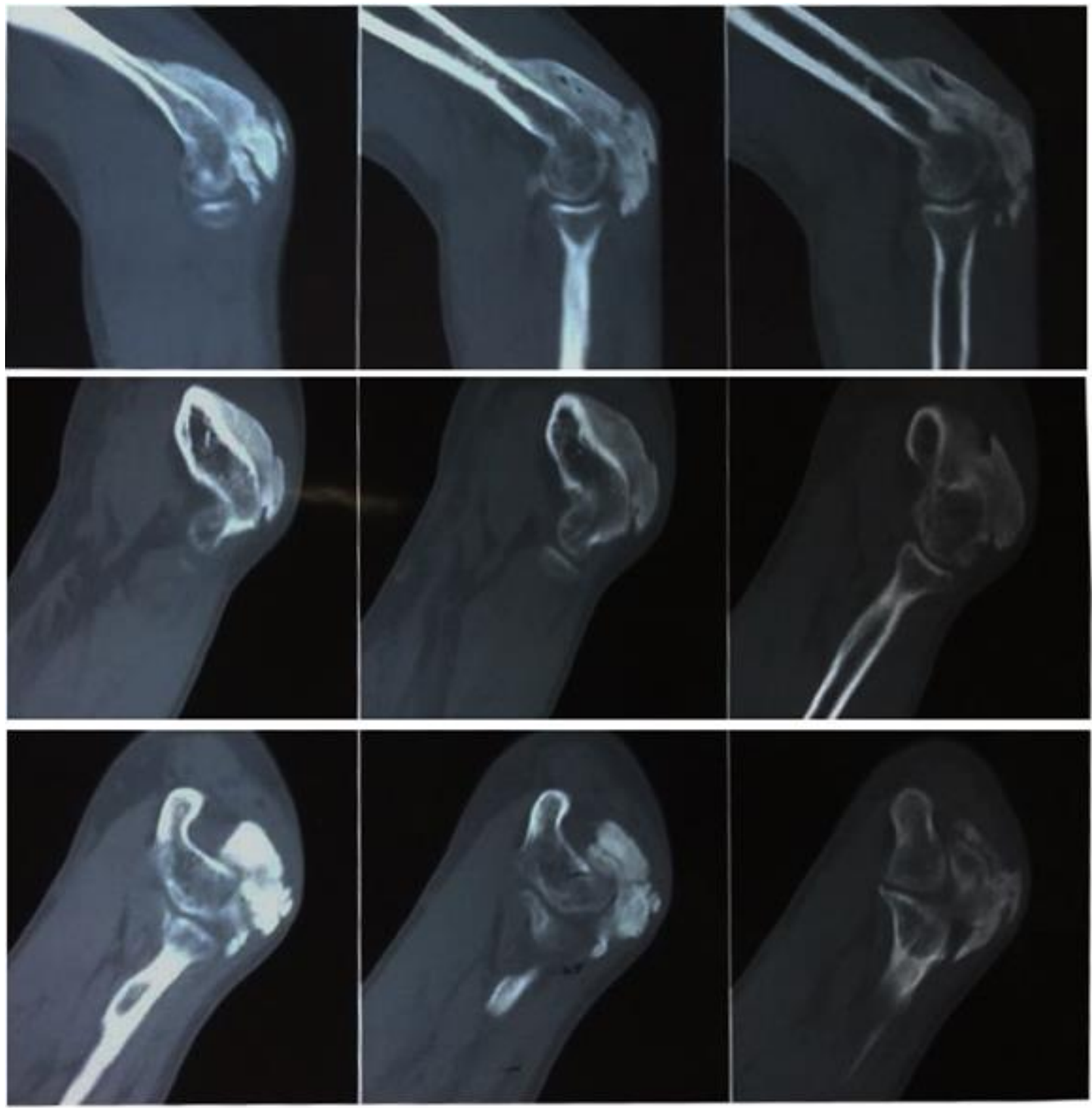

Fig 3: Computed Tomography image of right elbow showing mass arising from the posterior aspect of humerus

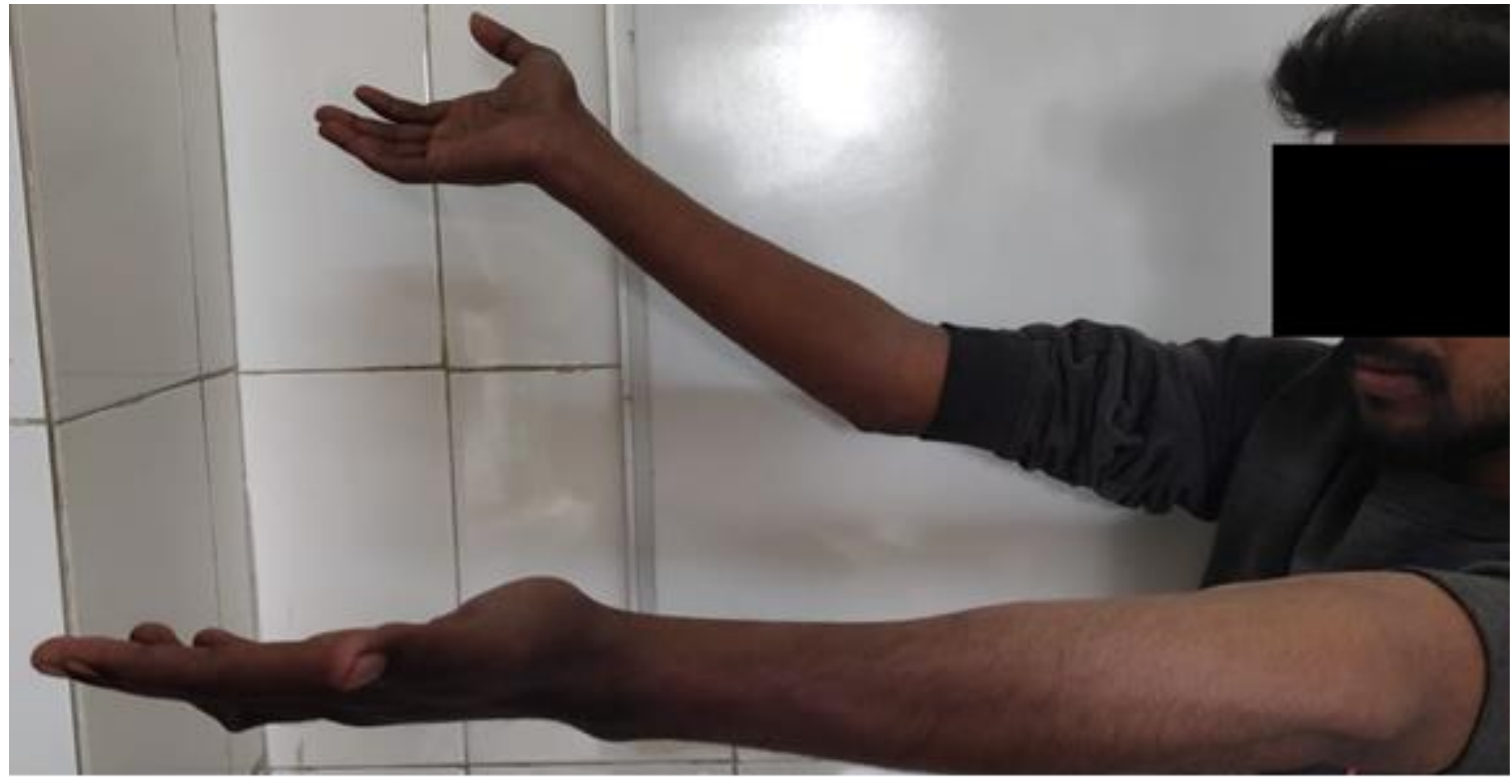

Fig 4: Pre-operative clinical image of right elbow showing $25^{0}$ of flexion deformity. 


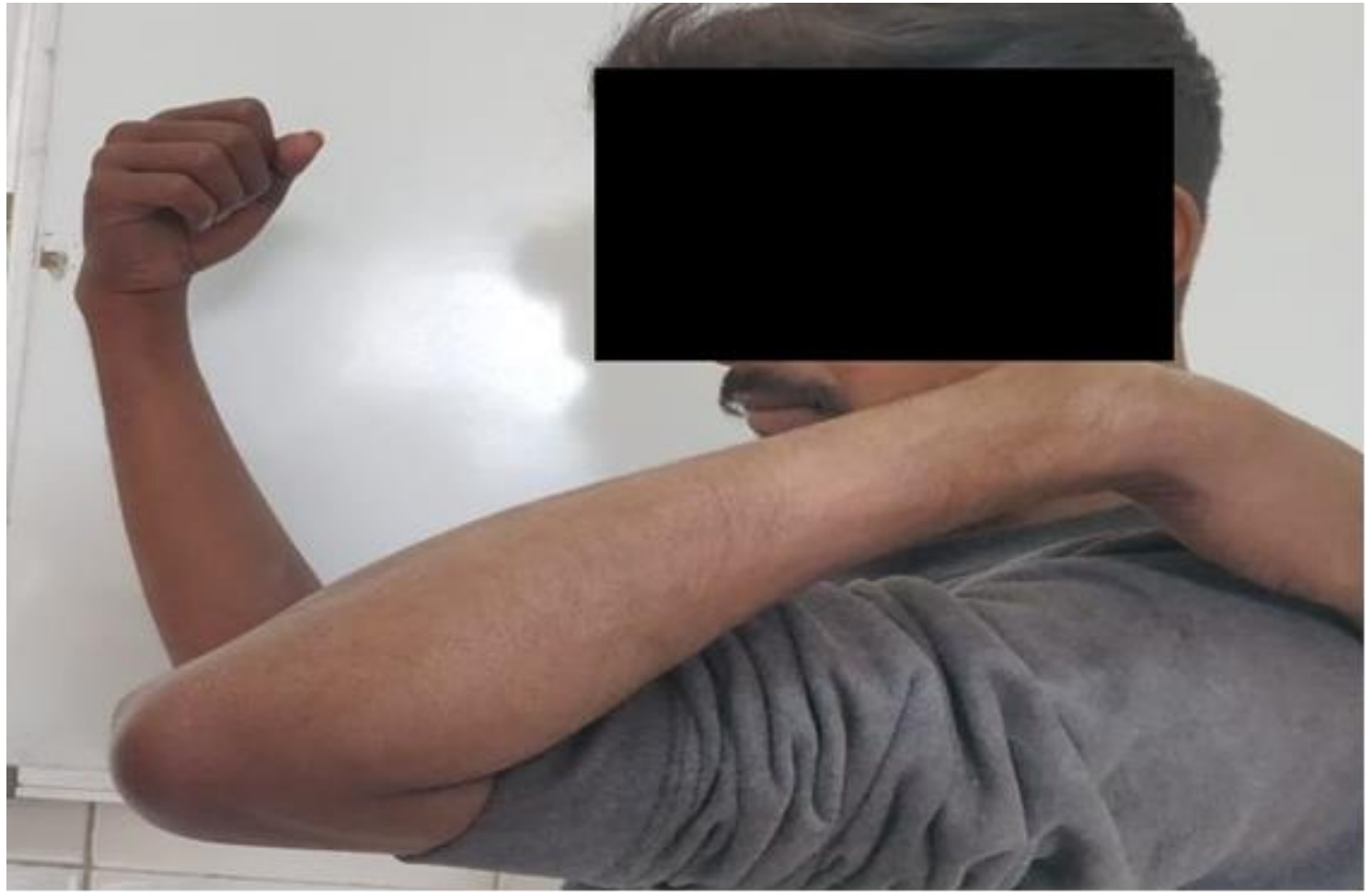

Fig 5: Pre-operative clinical image of right elbow showing flexion upto $80^{\circ}$.

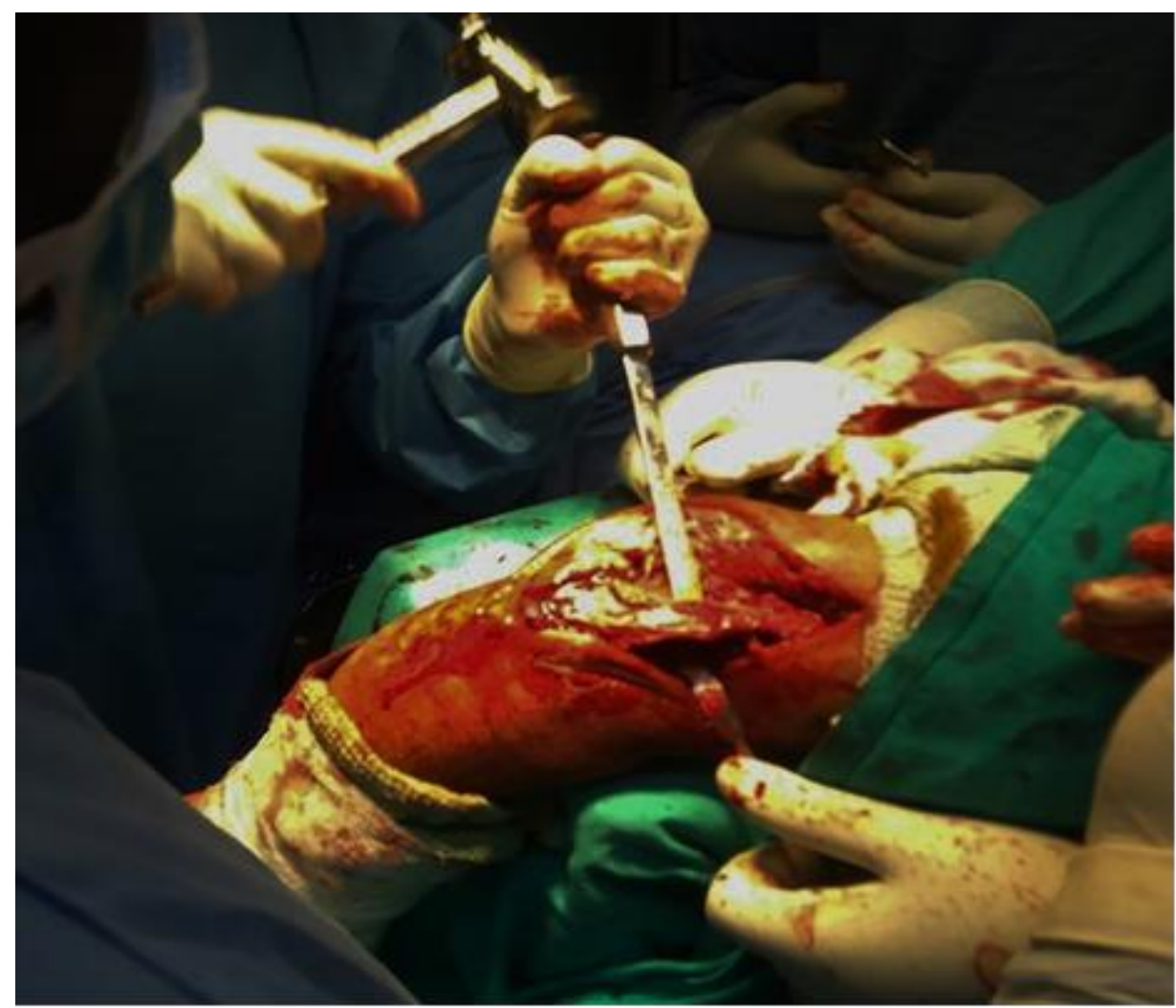

Fig 6: Intra-operative picture showing excision of myositis mass from posterior aspect of distal humerus. 


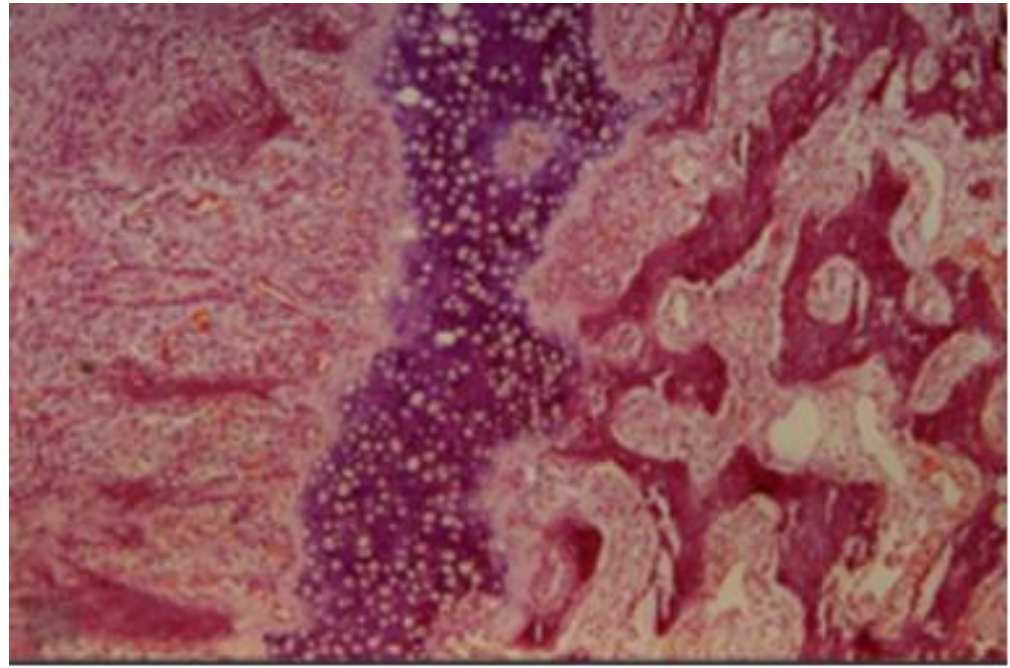

Fig 7: Post-operative histopathological image showing zonal phenomenon confirming myositis ossificans.

The patient was started on intravenous antibiotics and intramuscular analgesics for 5 days and was discharged. Tablet Indomethacin 50mg once daily was advised postoperatively. Range of movement exercises were started after suture removal in consultation with the physiotherapist. The patient was followed up and achieved a range of motion of flexion deformity of $15^{0}$ with further flexion upto $120^{\circ}$.

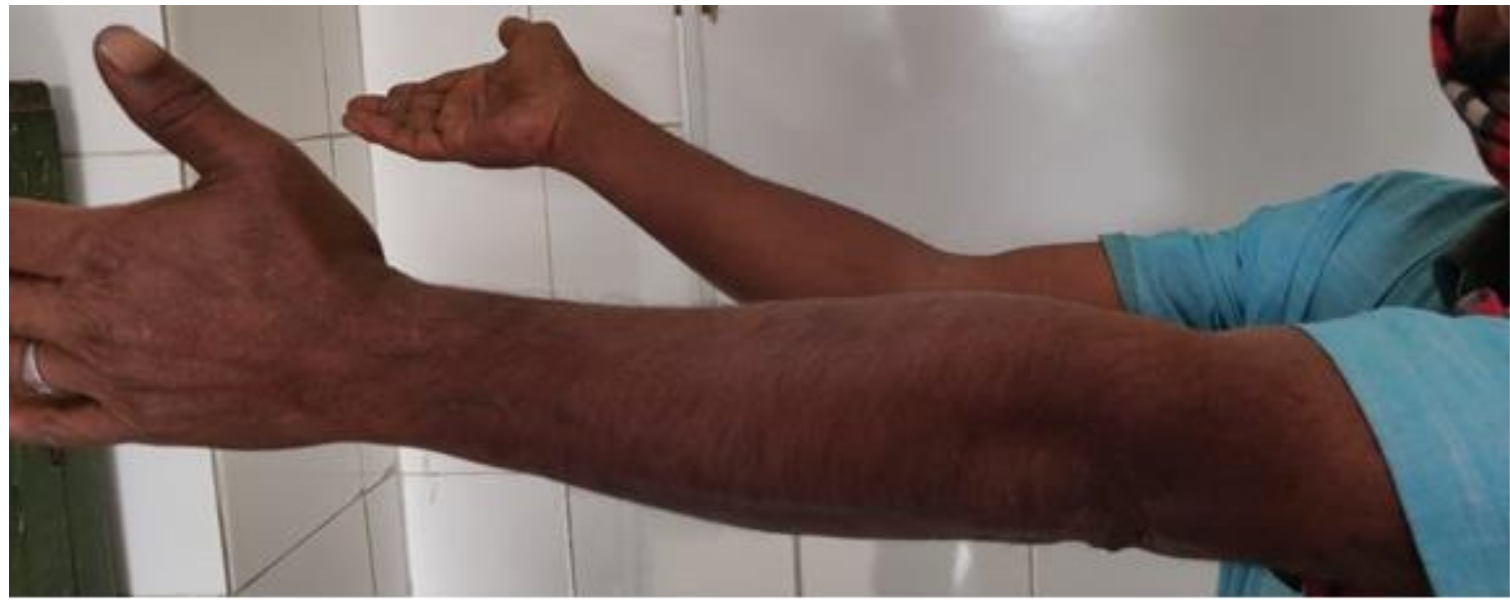

Fig 8: Post-operative clinical image taken 6 months post surgery showing residual flexion deformity of $15^{0}$.

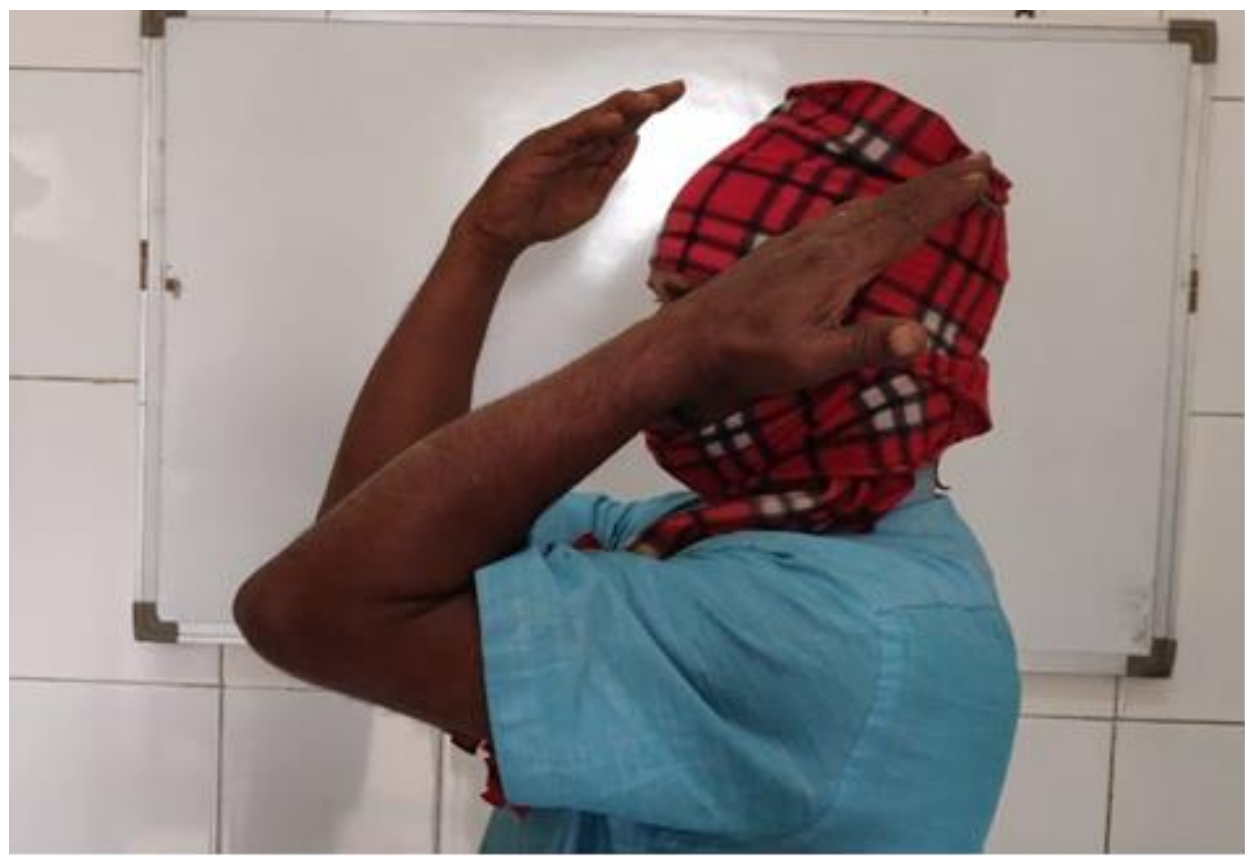

Fig 9: Post-operative clinical image taken after 6 months post-surgery showing flexion upto $120^{\circ}$ 


\section{Discussion}

Non traumatic myositis ossificans is extremely rare finding and usually develops due to spasm and stretching around the muscle and hematoma formation leading to ossification. This heterotopic ossification is caused by fibroblastic metaplasia or osteoblastic invagination of hematoma from damaged periosteum ${ }^{[3]}$. The reason for such myositis ossificans in tetanus patient is unknown. This was first described by Gunn and Young in their paper in 1959 and postulated that severe muscle spasm of tetanus may be the cause ${ }^{[4]}$. Dejerine, Ceillier and Dejerine were the first to describe ossification in muscles in traumatic paraplegia due to local tissue edema with alteration of in chemical composition of tissue fluids ${ }^{[5]}$. Brailsford suggested that lesion of central nervous system may be the common cause in these type of disorder ${ }^{[6]}$.

Myositis ossificans after tetanus is usually seen 6-8 weeks after onset of symptoms and elbow is most common location ${ }^{[8]}$. It is extremely rare with only 9 cases reported so far ${ }^{[9]}$. Our patient came with a history of restriction of movements and swelling around elbow which did not improve with antiinflammatory and physiotherapy. Surgical excision is required in cases limiting functional outcome followed by gentle active and passive range of movement exercises. Surgical excision should be performed when the lesion is in inactive stage ${ }^{[10]}$. There is no evidence to show the efficacy of antiinflammatory after diagnosis or after excision ${ }^{[11]}$.

Radiography can merely suspect myositis ossificans, but definite diagnosis is by biopsy showing zonal phenomenon and progression from periphery to center. Collagen producing cells are located in center and increased osteoblastic activity and immature bone lies in the intermediate zone and lamellar zone in the periphery ${ }^{[12]}$.

\section{Conclusion}

Based on the above findings we conclude that myositis ossificans after tetanus infection is an extremely rare finding and requires high index of suspicion. Surgical excision is required in cases with severe restriction of movements and post operative gentle flexion and extension exercises improve the functional outcome. Biopsy is required for confirmation of diagnosis and recurrence after resection is uncommon.

\section{Acknowledgment}

I thank all the staff and residents of Department of Orthopedics and Department of Pathology, Government Medical College, Kozhikode for their immense support in preparation of this case report.

\section{References}

1. Tsuno MM, Shu GJ. Myositis ossificans. J Manipulative Physiol Ther. 1990; 13(6):340-342.

2. Yunus OC, Muhammed Sefa Ozcan, Hasan Basri Sezer, Bekir Eray Kilinc, Osman Tugrul Eren. Nontraumatic Myositis Ossificans of Hip: A Case Presentation. Case Reports in Orthopedics. 2016; 2016(1982656):4 pages.

3. Meffert O, Weber HG. Beitrag zur Myositis ossificans localisata. Dtsch med Wschr. 1973; 98:653-656.

4. Gunn RD, Young WB. Myositis ossificans as a complication of tetanus. J Bone Joint Surg. 1959; 41B:535-540.

5. Dejerine Mme, Ceillier A, Dejerine Y. Para-osteoarthropathies des paraplegiques par lesion medullaire. Revue Neurologique. 1919; 26:339.

6. Brailsford JF. Changes in Bones, Joints and Soft Tissues Associated with Disease or Injury of the Central Nervous
System. British Journal of Radiology, N.S. 1941; 14:320.

7. Folpe AL, Inwards CY. Osteocartilaginous tumors," in Bone and Soft Tissue Pathology, J. X. O'Connell, Ed., A Volume in the Foundations in Diagnostic Pathology Series, Saunders-Elsevier, Philadelphia, Pa, USA, 2010, pp.239-254.

8. Karapinar H, Yagdi S. A case of myositis ossificans as a complication of tetanus treated by surgical excision. Acta Orthop Belg. 2003; 69(3):285-288.

9. Siwach S, Siwach R, Abrol L. Myositis ossificans in tetanus. A rare complication. The Journal of the Association of Physicians of India. 1990; 38:230-1.

10. Modabber MR, Jupiter JB. Reconstruction for posttraumatic conditions of the elbow joint (Current concepts review). J Bone Joint Surg. 1995; 77-A:14311446.

11. Garland DE, Blum CE, Waters RL. Periarticular heterotopic ossification in head-injured adults. Incidence and location. J Bone Joint Surg. 1980; 62-A:1143-1146.

12. Zoccali C, Chichierchia G, Covello R. An unusual case of lumbar paravertebral miositis ossificans mimicking muscular skeletal tumor. Musculoskeletal Surgery. 2013; 97(3):251-253. 